\title{
Religious Coping as a Predictor of the Burden of Care in the Caregivers of End-stage Cancer Patients
}

\author{
Mohaddeseh Rajabi ${ }^{1}$, Malek Bastami ${ }^{2}$, Neda Shahvaroughi Farahani ${ }^{3}$, \\ Amir Hossein Tavanaie ${ }^{4},{ }^{*}$ Behrouz Ghanbari $^{5}$, Haniyeh Alasti ${ }^{6}$
}

\begin{abstract}
Background \& Aims: Advanced cancer is accompanied by physical, mental, and social complications in the patients. During the diagnosis and treatment processes, the necessary care is provided to the patient by formal caregivers for only a short period at the hospital; in other cases, the care is provided by informal caregivers. Informal caregivers are untrained individuals who are not paid for care provision, delivering care to their family members and close relatives. Under such circumstances, if the caregiver is not able to manage the caretaking time and their personal time, they will become prone to caregiver burden. Caregiver burden has a covert and personal nature, encompassing components such as time-related, evolutionary, physical, social, and emotional caregiver burden. The concept has external and internal dimensions; the external dimension of caregiver burden consists of the factors that are related to the patient, such as attention to the patients' needs, allocating time to the patients, and the provided services for the recovery of the patients. Internal caregiver burden involves personal beliefs, angers, internal emotions, and the individual's sense of importance toward the role of the caregiver. Meanwhile, coping strategies are the internal factors used by caregivers in the face of life tensions. In this regard, the role of religion as a strategy for coping with stress is considered as a form of defensive mechanism in a positive view (benevolent religious reappraisal, reappraisal of God's power, seeking spiritual support, collaborative religious coping, religious purification, religious redemption, religious helping, religious focus, spiritual connection, and seeking support from clergies) and a negative view (reappraisal of the punishing God, active/passive deference, self-directing religious coping, demonic reappraisal, spiritual discontent, and interpersonal religious discontent). Despite the importance of coping strategies and role of religion as an index that has been constantly emphasized in facing difficulties and adversities, it remains unclear in the literature whether religious coping could predict the caregiver burden of the caregivers of advanced cancer patients. Although extensive research has been conducted in this regard, further investigations should be focused on end-stage cancer patients and their caregivers. The present study aimed to predict the burden toleration among end-stage cancer patient caregivers based on their religious coping styles.

Materials \& Methods: This cross-sectional, correlational study was conducted on the caregivers of endstage cancer patients referring to the palliative care center of Firoozgar Hospital in Tehran, Iran during April-September 2017. In total, 154 individuals were selected via convenience sampling based on Tabachnick and Fidell sample size estimation method. The inclusion criteria were the minimum caregiving period of one month, disease course and treatment (end-stage patients requiring a main caregiver for fulltime care), basic literacy (ability to read and write), age of 15-75 years, Iranian nationality, and willingness to participate in the research. The exclusion criterion was the diagnosis of psychotic disorders in the patients affecting the interview process and validity of responses. Data were collected using the caregiver burden

1. MS in Clinical Psychology, Firoozgar Clinical Research Development Center (FCRDC), Iran University of Medical Sciences, Tehran, Iran.

${ }^{2}$ PhD Candidate in Health Psychology, School of Psychology and Educational Sciences, University of Tehran, Tehran, Iran

${ }^{3}$ PhD Candidate in Psychology, School of Psychology and Educational Sciences, Allame Tabataba'i University, Tehran, Iran

${ }^{4}$ MS in Clinical Psychology, ALA Cancer Prevention and Control Center, Firoozgar Hospital, University of Tehran, Tehran, Iran

${ }^{5}$ Assistant Professor, Gastrointestinal and Liver Disease Research Center (GILDRC), Iran University of Medical Sciences, Tehran, Iran. (*Corresponding author) Tel: $09123480128 \quad$ Email: ghanbari.b@iums.ac.ir

${ }^{6}$ PhD Candidate in Health Psychology, School of Psychology and Educational Sciences, Kharazmi University, Tehran, Iran
\end{abstract}


inventory by Guest and Novak and the religious coping questionnaire (RCOPE) by Pargament with 14 items. Data analysis was performed in SPSS version 16 using Pearson's correlation-coefficient and multiple regression analysis simultaneously.

Results: Out of 146 participants, $71(48.6 \%)$ were male and 75 (51.4\%) were female within the age range of 15-72 years. No significant association was observed between the positive religious coping style and caregiver burden, while the negative religious coping style was positively and significantly correlated with the caregiver burden, with the correlation level of $34 \%$. Furthermore, the negative religious coping style $(\mathrm{t}=4.444 ; \beta=0.352)$ could significantly predict the caregiver burden, while the positive religious coping $(\mathrm{t}=0.438 ; \beta=0.035)$ could not significantly explain the caregiver burden.

Conclusion: According to the results, the positive religious coping style and caregiver burden had no significant correlation, while the association between negative religious coping style and caregiver burden was positive and significant. Therefore, using the negative religious coping styles could reduce mental health and increase the caregiver burden. In fact, as a dimension of spirituality and a coping style, religion could result in the reduction of tensions, and the World Health Organization (WHO) has also acknowledged spirituality as a fundamental factor to enhance mental health. On the other hand, the positive religious coping style could not predict the caregiver burden in this study. Long-term and extensive care provided to endstage cancer patients by the caregivers may reduce the effectiveness of coping strategies (e.g., positive coping styles) in the reduction of the caregiver burden due to the prolonged disease course and treatment process. Our findings also indicated that the negative religious coping style exerted a negative impact on the burden tolerance of the caregivers of the end-stage cancer patients, exposing these individuals to a higher sense of burden and reduced quality of life. As such, training on coping skills with a focus on improving positive religious coping strategies in the caregivers of cancer patients since the initial stages of the disease could be an effective step toward reducing the caregiver burden incurred upon these caregivers during the treatment process. In conclusion, it is recommended that the results of this study be incorporated into the psychological services provided to the caregivers of end-stage cancer patients in order to decrease their burden.

Keywords: Caregiver Burden, Religious Coping, Caregivers, Cancer

\section{Conflict of Interest: No}

How to Cite: Rajabi M., Bastami M., Shahvaroughi Farahani N., Tavanaie Ah., Ghanbari B., Alasti H. Religious Coping as a Predictor of the Burden of Care in the Caregivers of End-Stage Cancer Patients. Iran Journal of Nursing. 2018; 31(114):6-18.

Received: 7 Jul 2018

Accepted: 6 Oct 2018 


\section{يشيشى فشار مر اقبتى بر اساس مقابلدى مذهبى در مراقبين بيماران مبتلا به سرطان مراحل انتهايى}

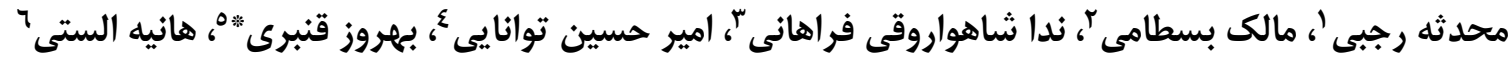

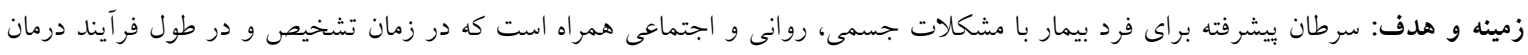

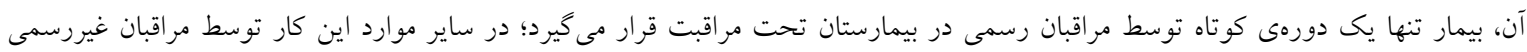

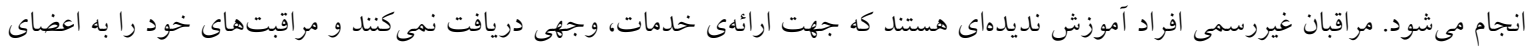

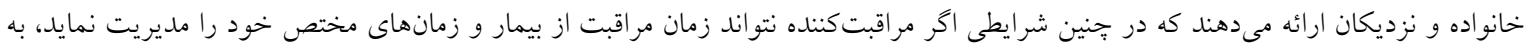

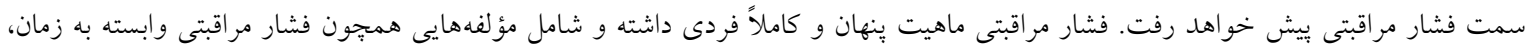

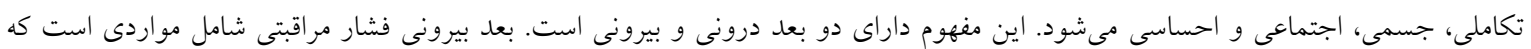

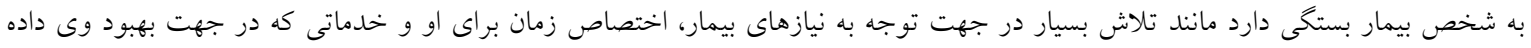

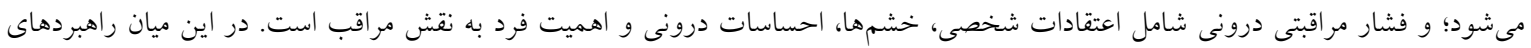

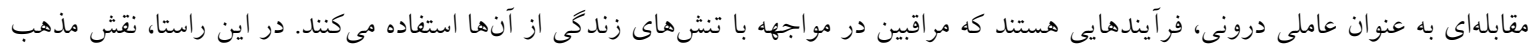

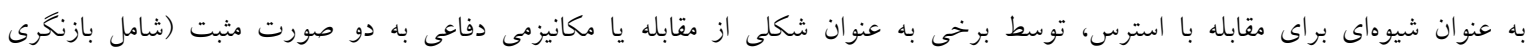

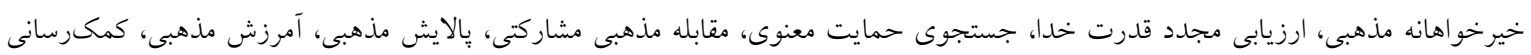

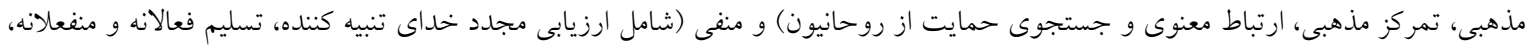

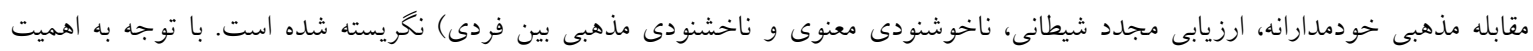

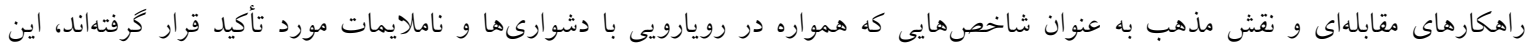

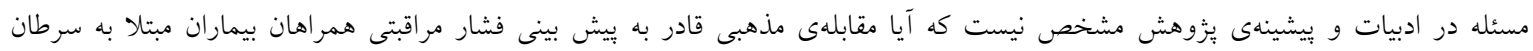

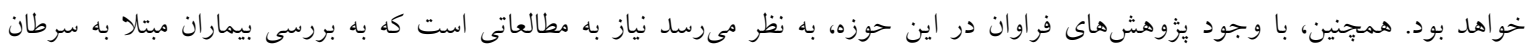

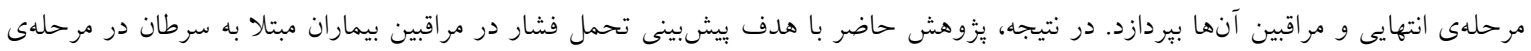

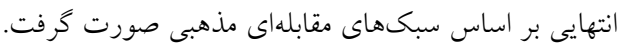

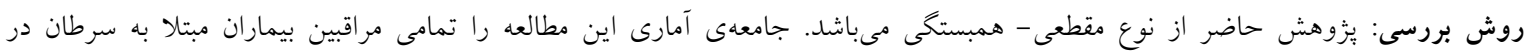

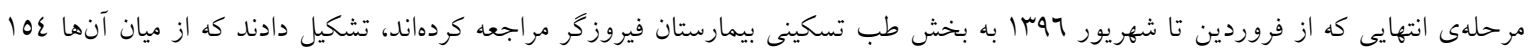

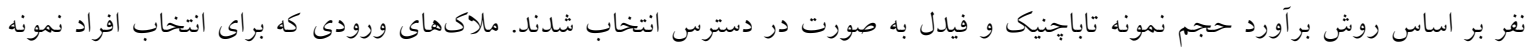

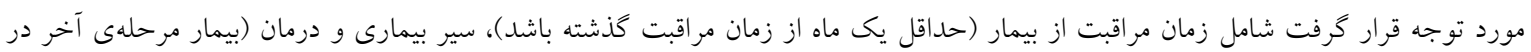

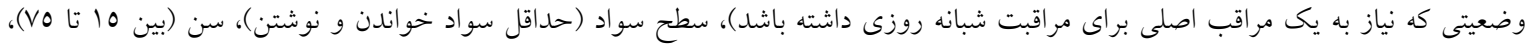

' '. كارشناسى ارشد روانشناسى بالينى، مركز توسعه تحقيقات بالينى بيمارستان فيروزتر، دانشكاه علوم يزشكى ايران، تهران، ايران.

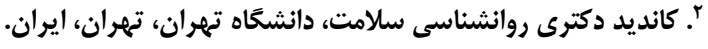

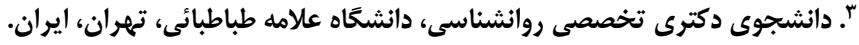

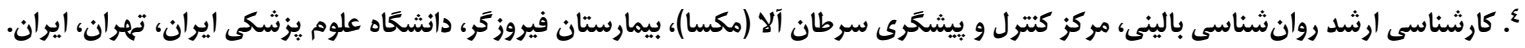

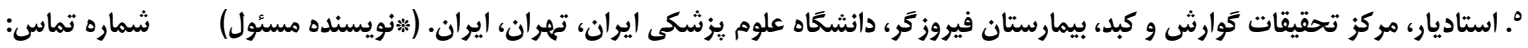




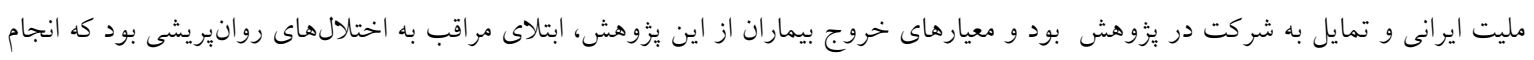

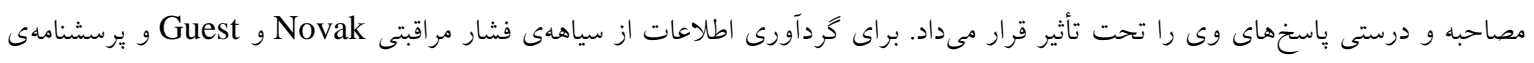

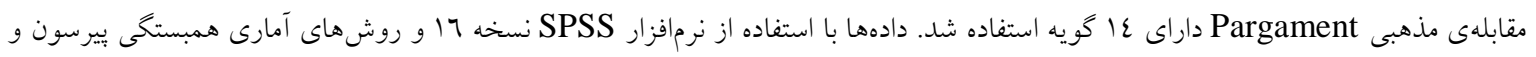

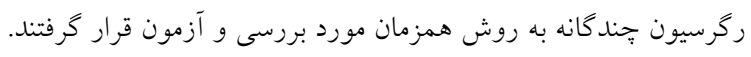

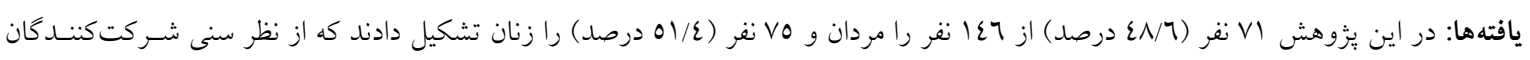

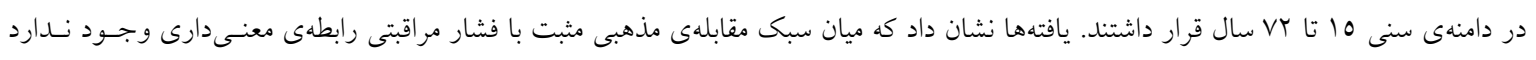

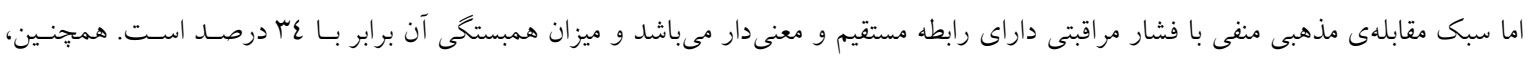

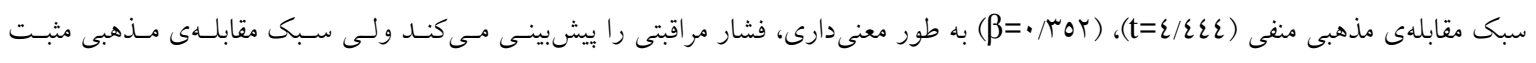

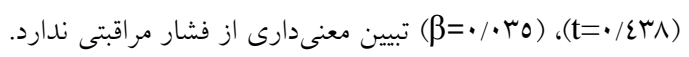

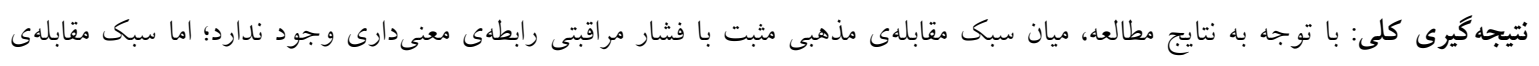

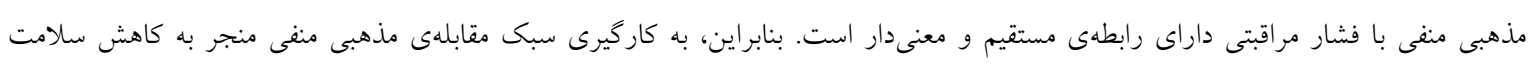

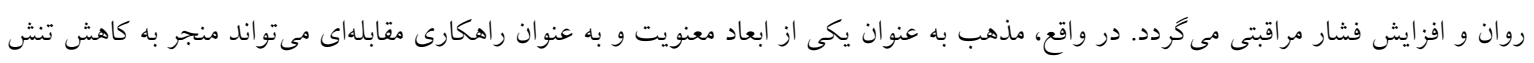

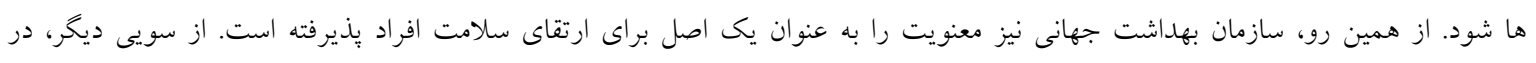

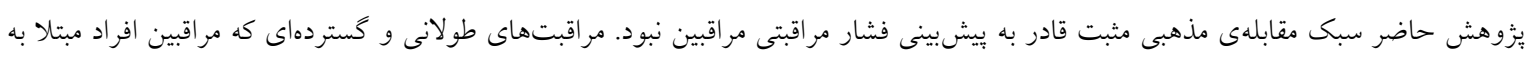

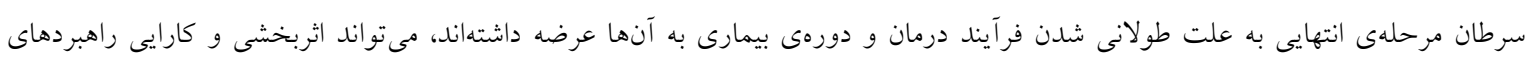

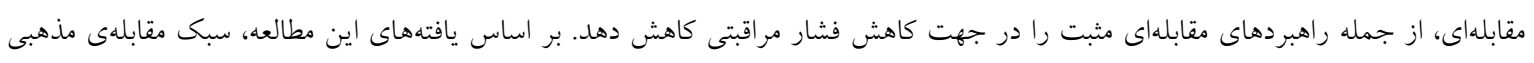

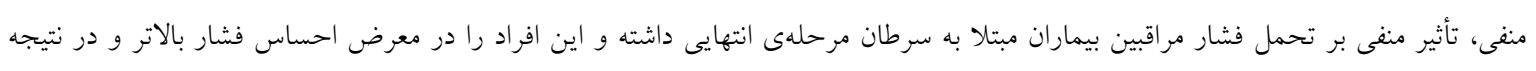

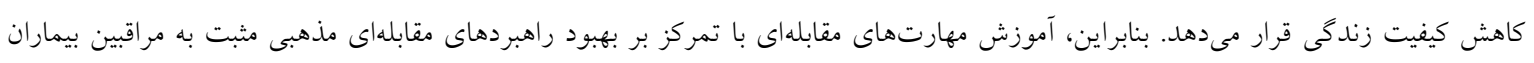

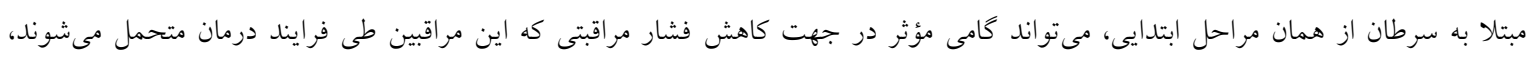

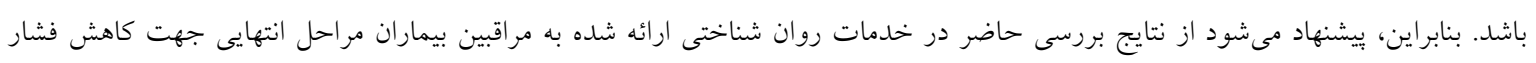
مراقبتى آنها استفاده شود.

\section{كليدوازهها: فشار مراقبتى، مقابله مذهبى، مراقبين، سرطان.}

تضاد منافع: ندارد

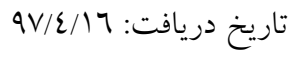

تاريخ بذيرش: QV/V/I 
نيازهاى بيمار، اختصاص زمان براى او و خدماتى كه در

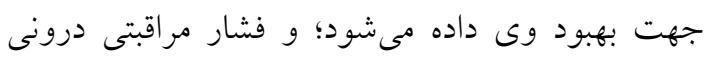

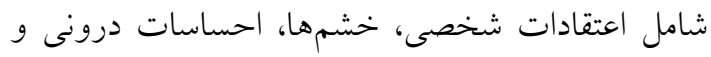

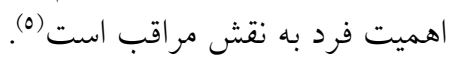

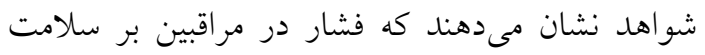

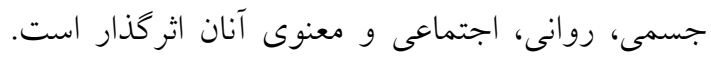

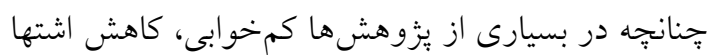

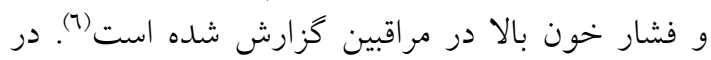

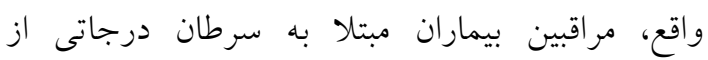

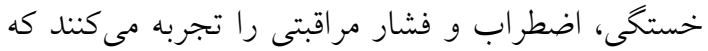

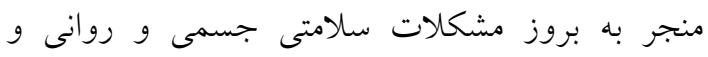

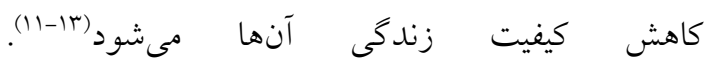
Goldzweig و همكاران با برزسى مراقبين بيماران

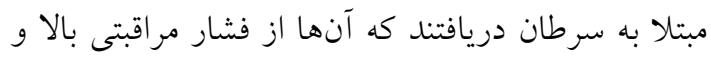
حمايت هيجانى كمى برخوردار هستند و مهارتهات بناي

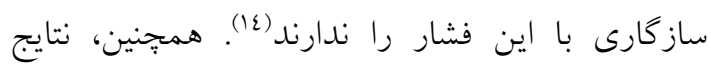

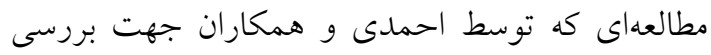

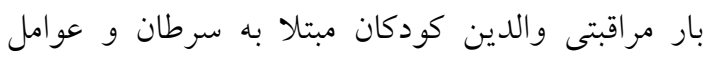

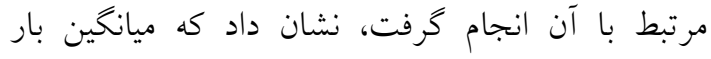

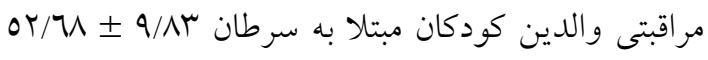

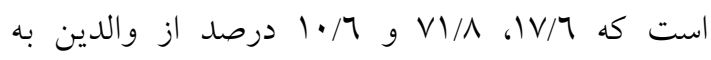

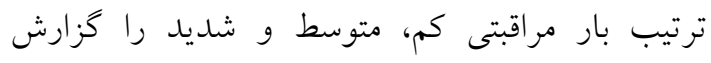

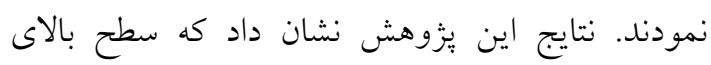

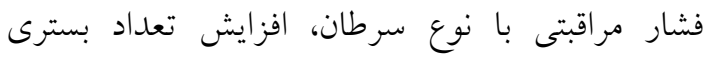

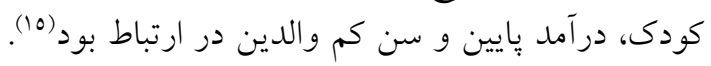

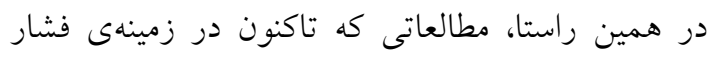

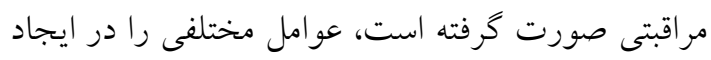

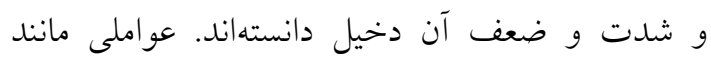

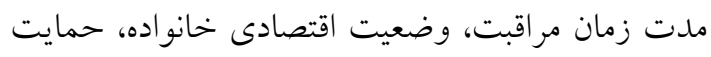

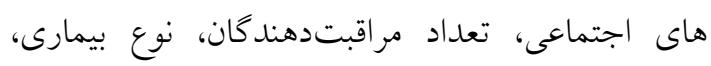

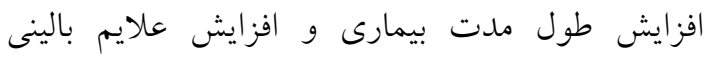

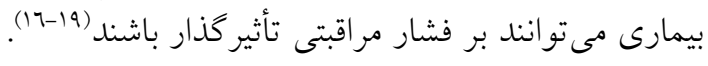

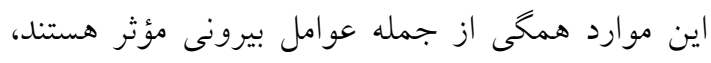

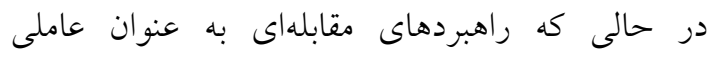

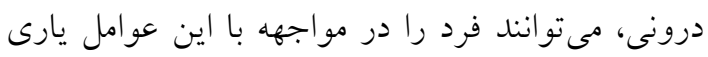

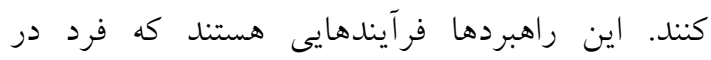

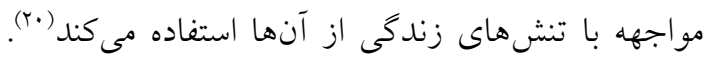

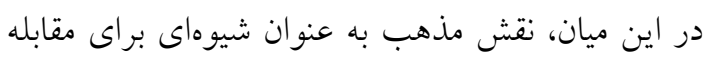

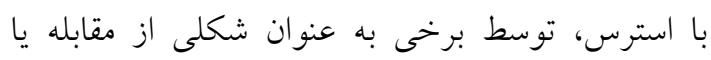

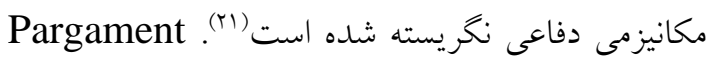
معتقد است كه مدل نظرى الكوى مقابلهى مذهبى مى نكئل

\section{مقدمه}

سرطان به عنوان يكى از مشكلات عمدهى يزشكى و از

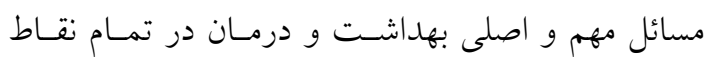

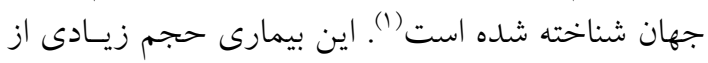

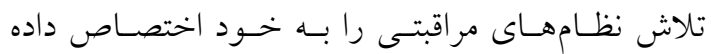

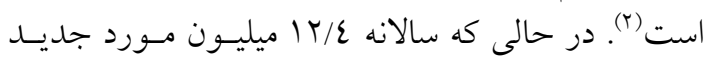

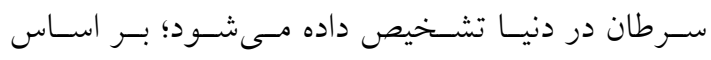

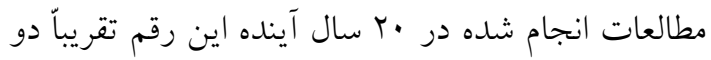

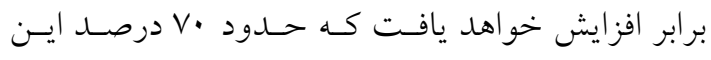

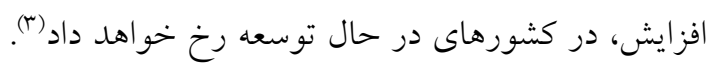

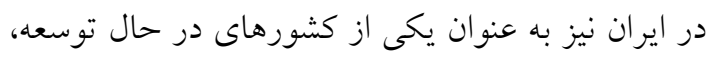

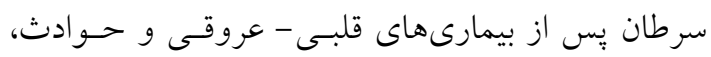

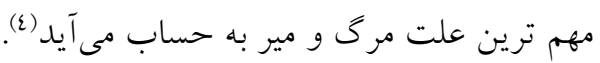

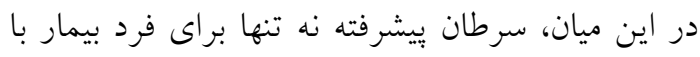

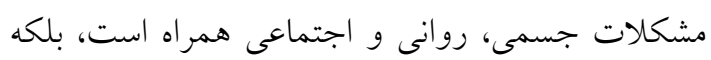

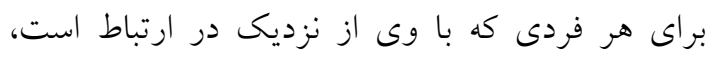

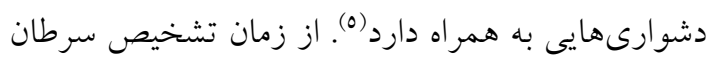

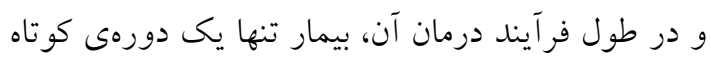

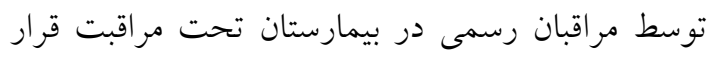

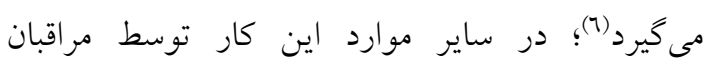

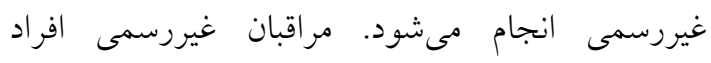

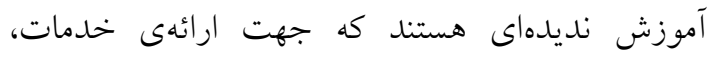

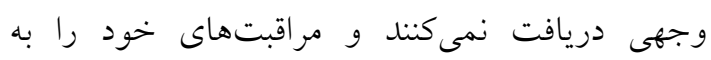

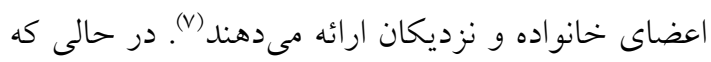

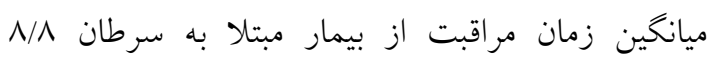

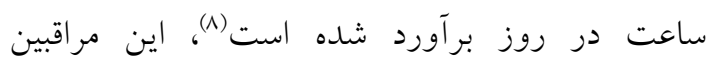

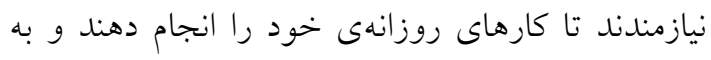

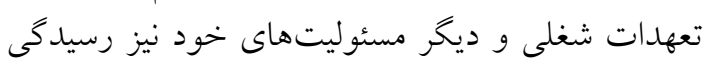

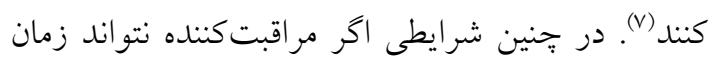

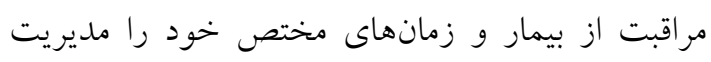

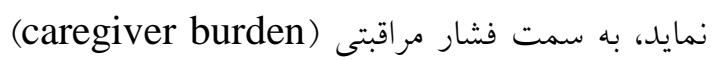

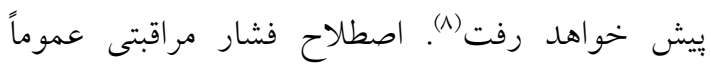

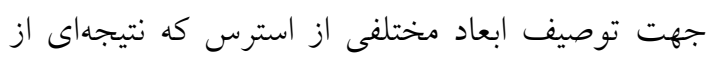

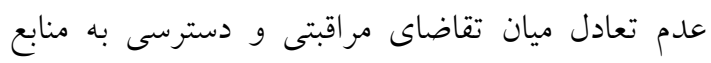

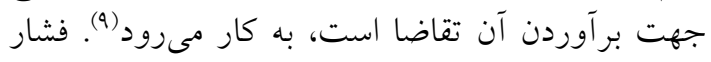

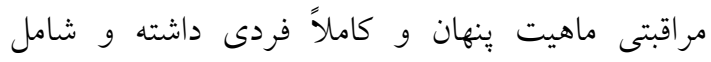

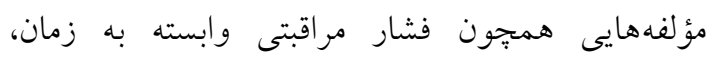

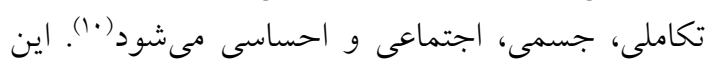

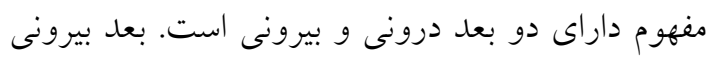

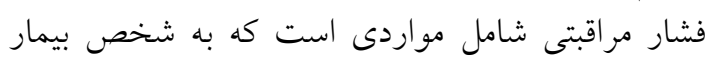

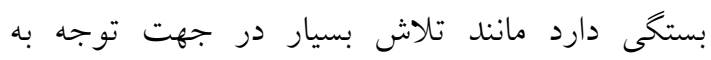


فرسودگى مراقبتى در مراقبين خانوادكى رابطهى معنى

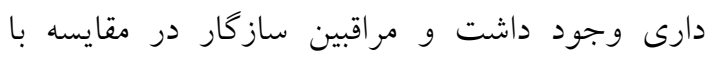

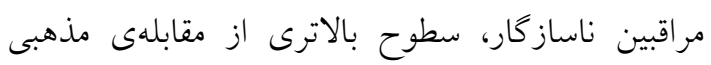

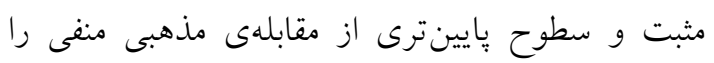
كز ارش نمودند

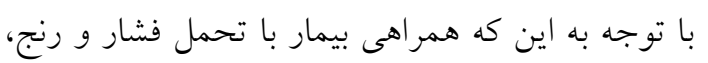

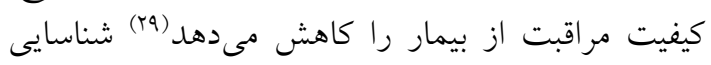

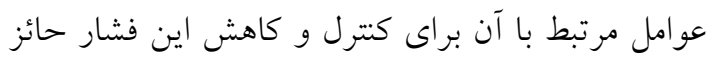

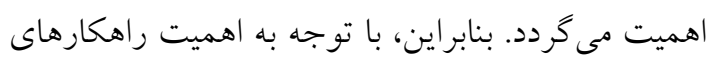

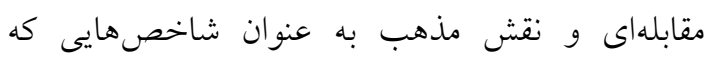
همواره در رويارويى با دشوارىها و و ناملايمات منات مورد

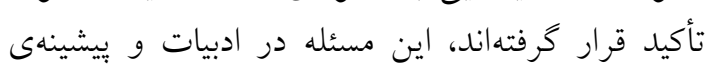

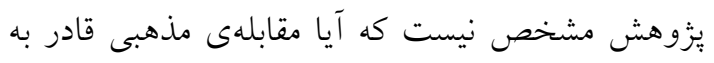

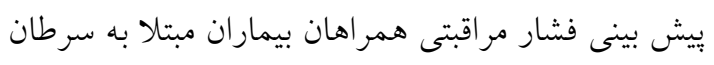

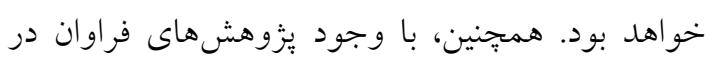

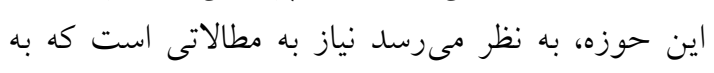

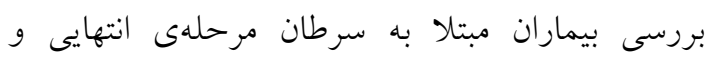

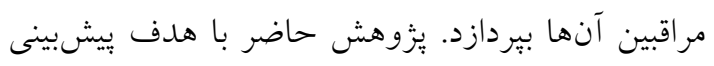

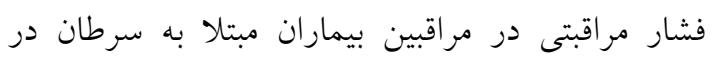

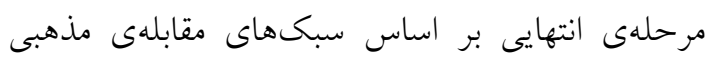

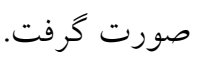

\section{روش بررسى - - ماضى}

مطالعهى حاضر يكى مطالعهى مقطعى - همبستخى

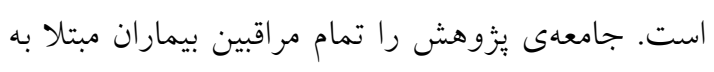

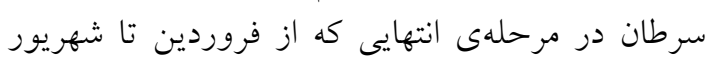

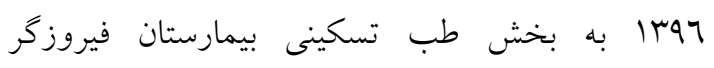

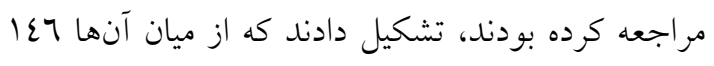

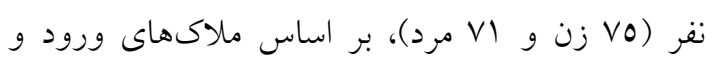

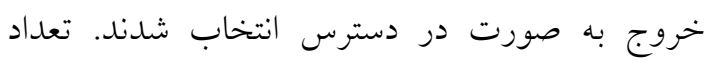

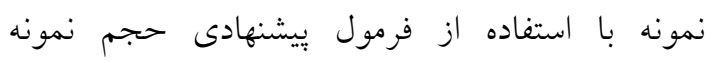

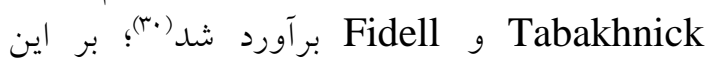
اساس، حداقل حجم نمونه در مطالعات همبستخى از

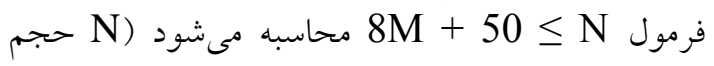

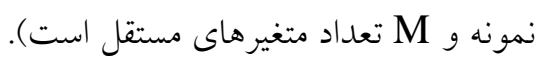

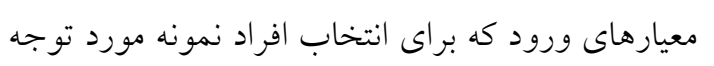

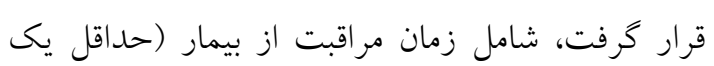
ماه از زمان مراقبت كخدشته باشد)، سير بيمارى و و درمان

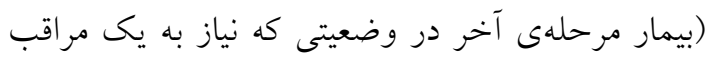

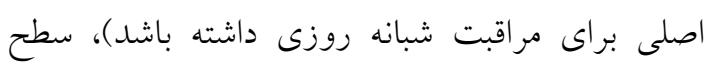
سواد (حداقل سواد خواندن و نوشتن) و سن (بين 10

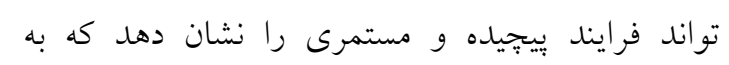

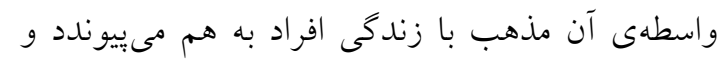

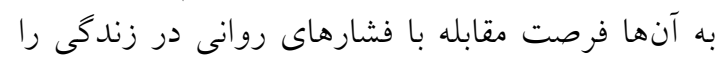

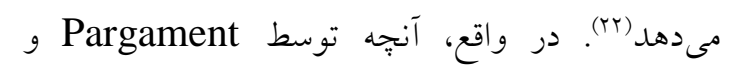
همكاران به عنوان كاركردهاى كليدى مذهب آنجه ترسط شناسايى

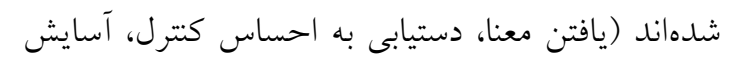

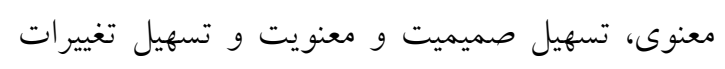
عميق زندكى) نشان دهندهى اهميت راهبردهائ وهاى مقابله

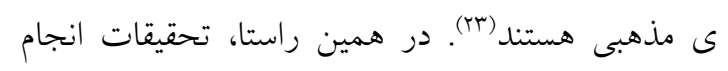

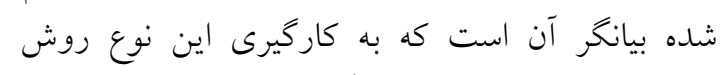

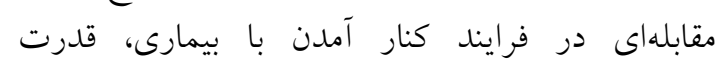

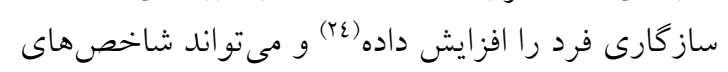

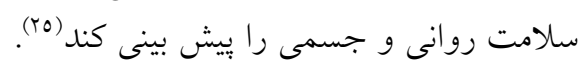

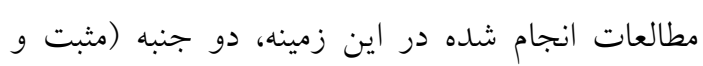

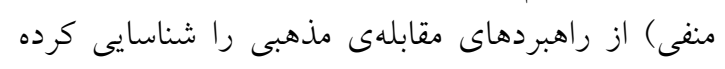

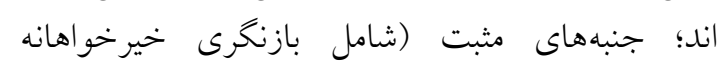

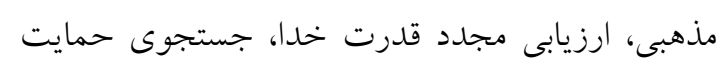

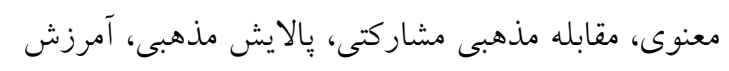

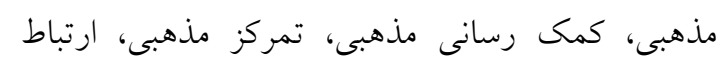

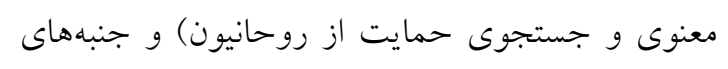

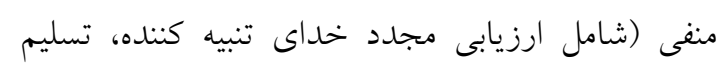

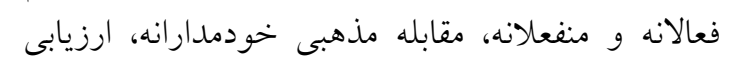

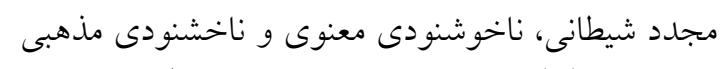

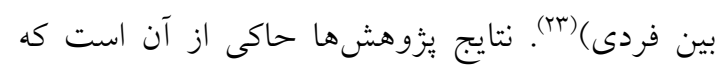

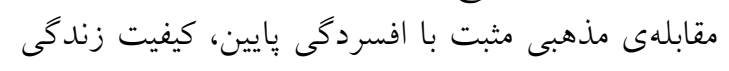

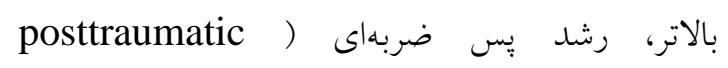
و و تشريك مساعى بيشتر در ميان بيماران (growth

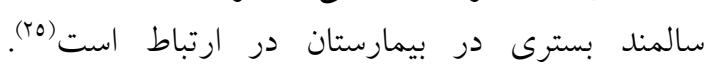

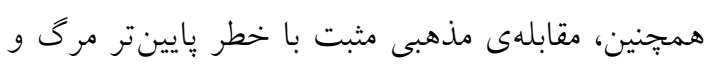

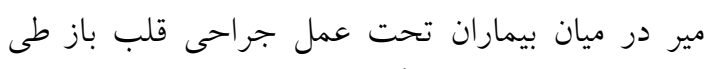

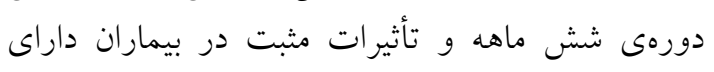

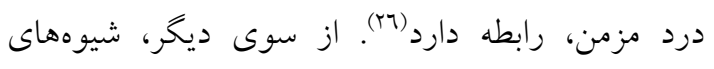

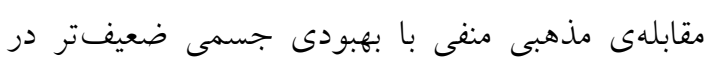

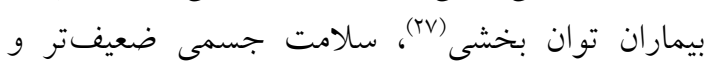

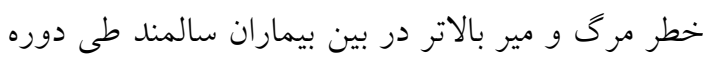

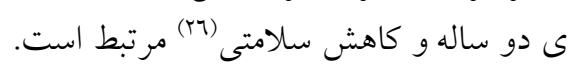

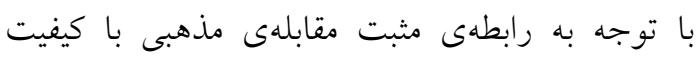

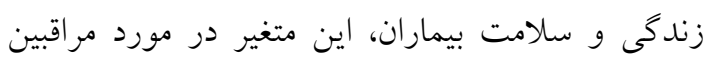

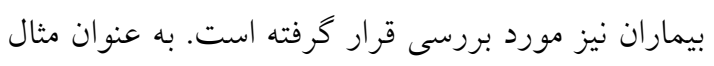

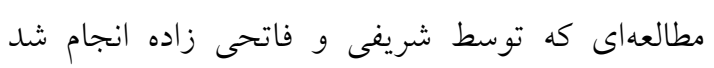

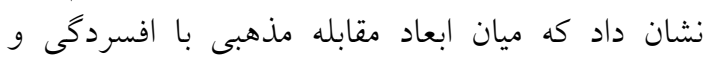


و سئوالات 1 الى عا عائ براى راهبردهاى منفى در نظر

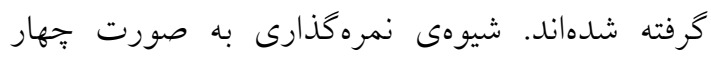

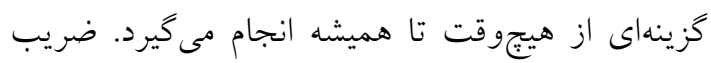

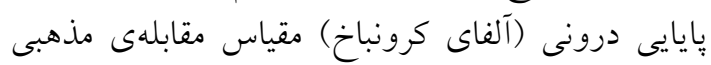

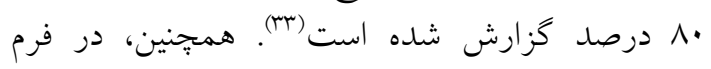

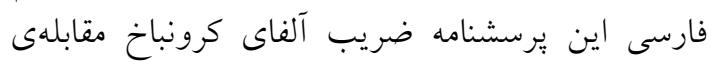

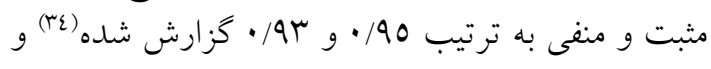

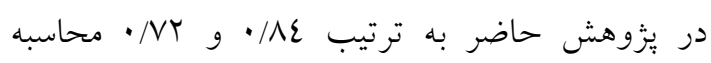
كرديد. دادهها با استفاده از نرمافزار SPSS، ويرديل ويرايش 17 و و

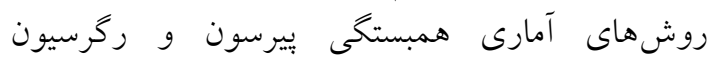

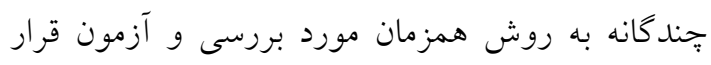

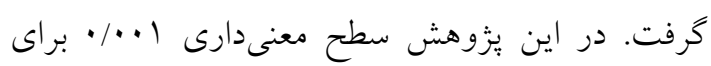
معنى دارى آزمونهاى آمارى لحاظ كردين ئريد.

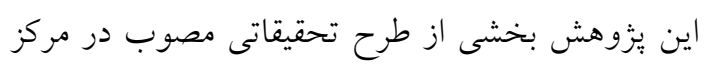

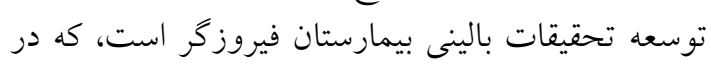

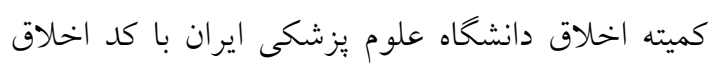


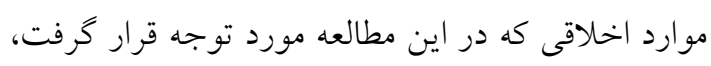

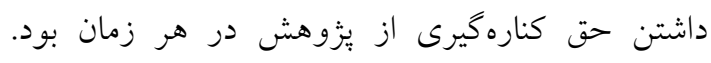

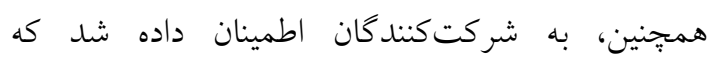

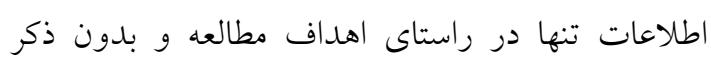

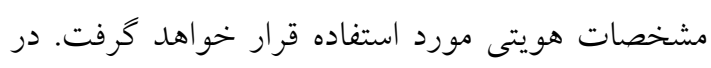

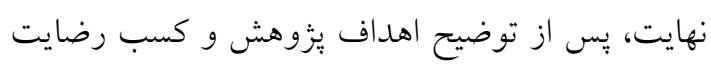

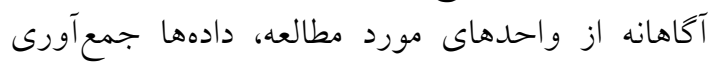

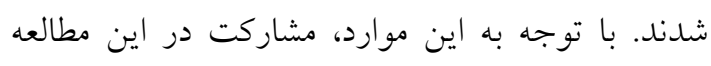

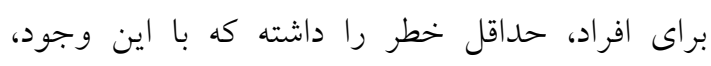

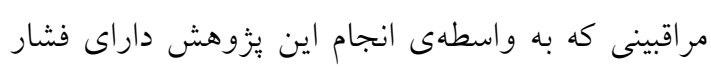

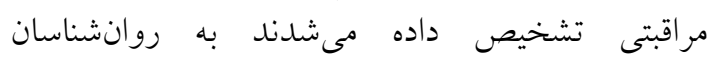
متخصص در بخش طب تسكينى ارجاع داده مى شدند.

\section{يافتهها}

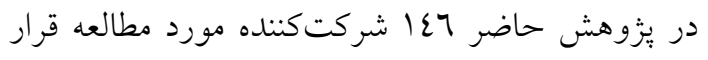

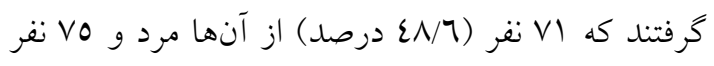

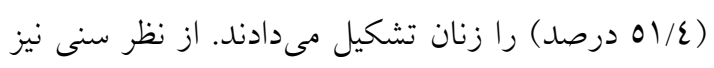

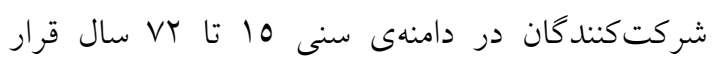

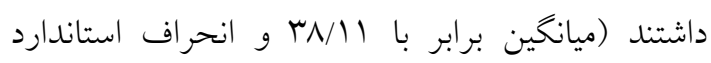

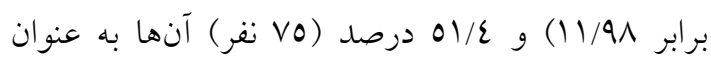

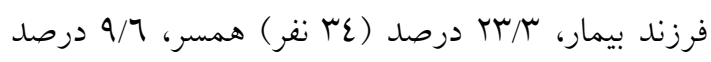

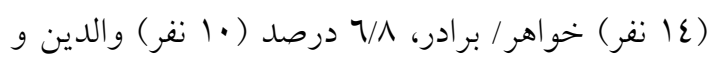

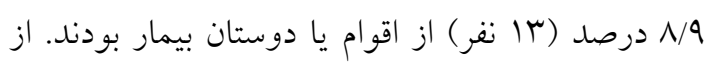

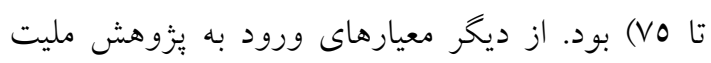

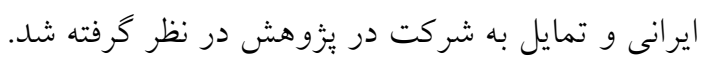

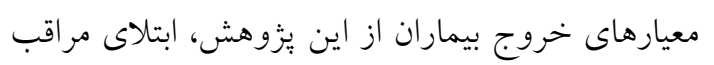

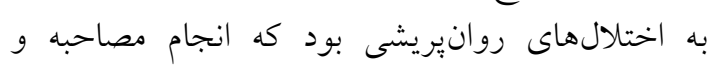

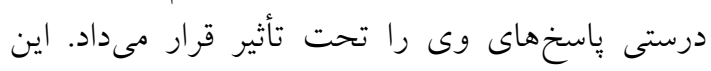

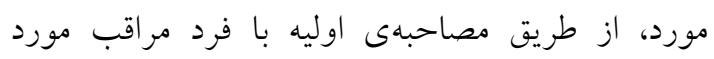

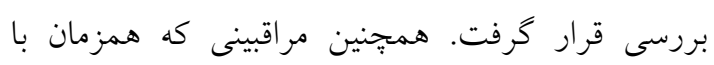

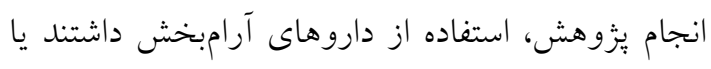

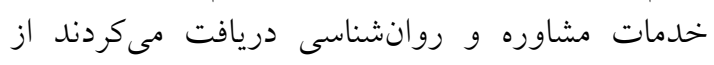
مطالعه خارج شدند. جهت كردآورى دادهها از فرم اطلاعات فردى، سياهنى

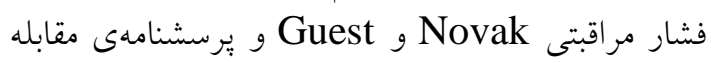

ى مذهبى استفاده شد: الف) برسشنامهى اطلاعات فرهات فردى: اين برسشنامه كه

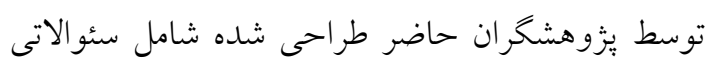

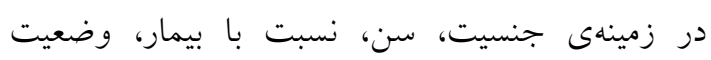
اقتصادى و بينش بيمار نسبت به بيمارى است.

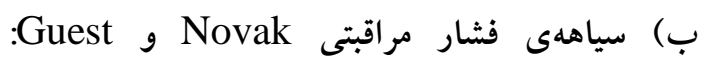
سياهلى فشار مراقبتى ع كب كويه دارد كه در سال 1919

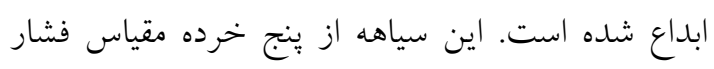

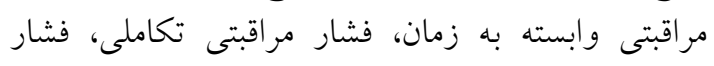

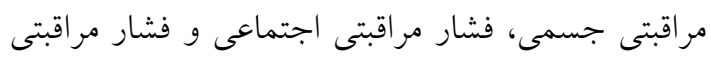

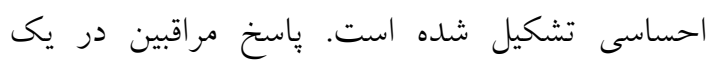

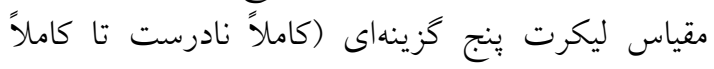

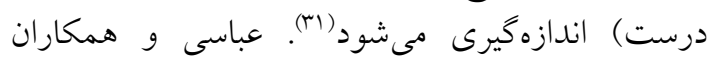

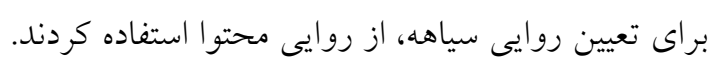

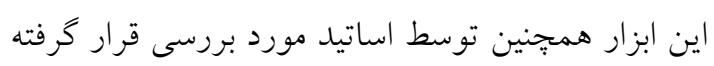

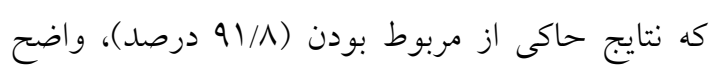

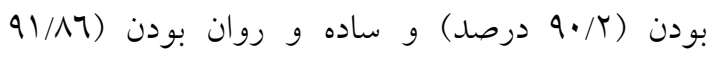

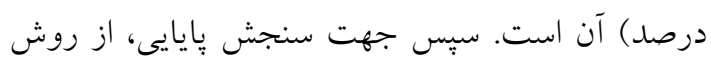

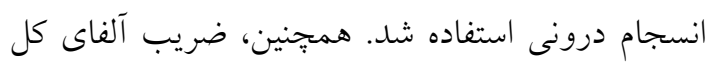

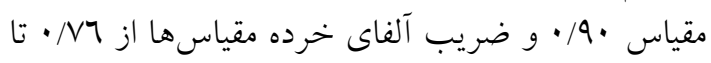

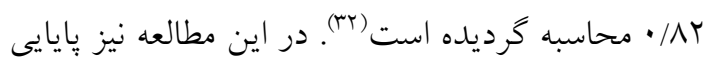

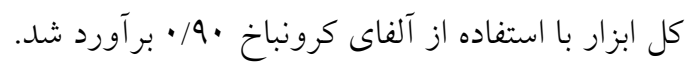

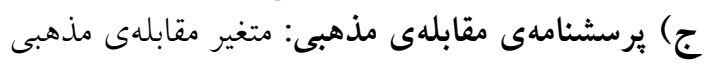

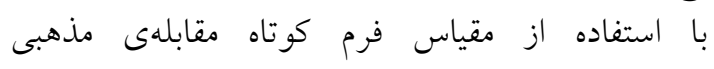
Pargament

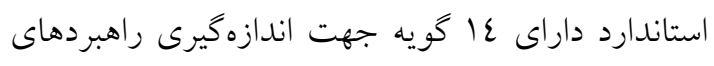

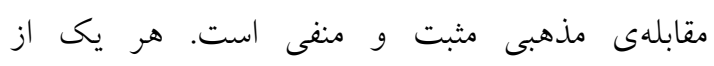
مقياسهاى مثبت و منفى شامل هفت منت ماده از ماز آزمون

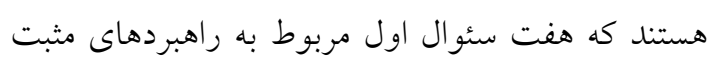




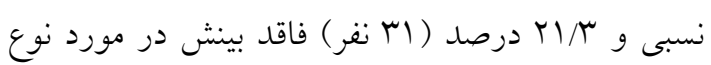

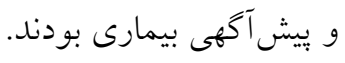

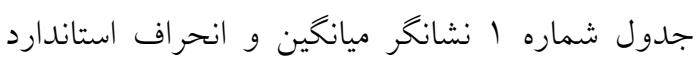

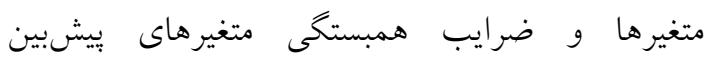

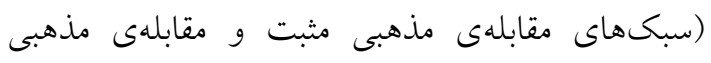

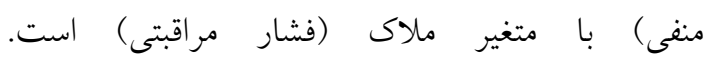

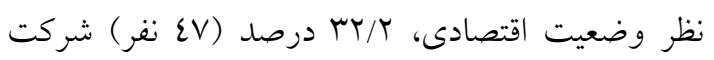

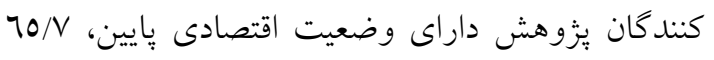

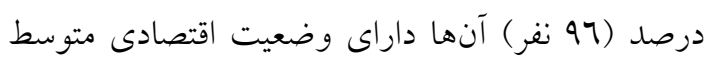

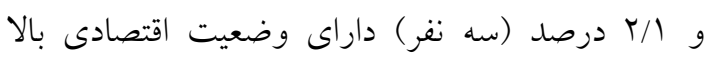
بودند. از نظر سطح بينش

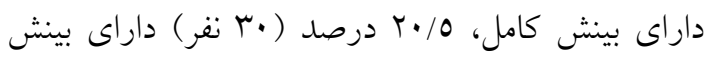

جدول شماره ا: ميانكَين، انحراف استاندارد و همبستكى متغيرهاى سبكهاى مقابلهى مذهبى مثبت و مقابلهى مذهبى منفى با فشار

\begin{tabular}{|c|c|c|c|c|}
\hline & فشار مراقبتى & SD & $\mathbf{M}$ & \\
\hline $\mathrm{P}$ & ضريب همبستكى بير سون & IV/O. & $09 / r^{\prime}$ & فشار مر اقبتى \\
\hline$\cdot / \varepsilon r V$ &.$- / \cdot 1$ & $\varepsilon / \pi)$ & $17 / \varepsilon \cdot$ & مقابلهى مذهبى مثبت \\
\hline$\cdot / \cdot 1$ & 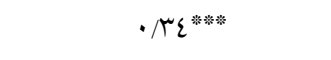 & $1 / \pi V$ & $1 / 10$ & مقابلهى مذهبى منفى \\
\hline
\end{tabular}

$* * * \mathrm{P}<\cdot / \cdots 1$

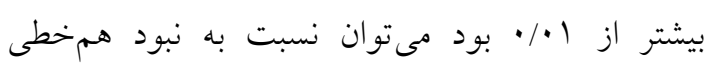
اطمينان حاصل كرد.

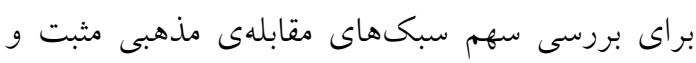

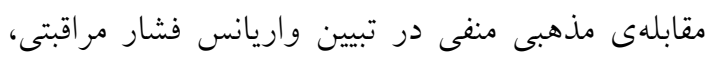

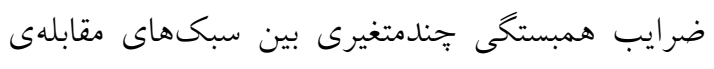

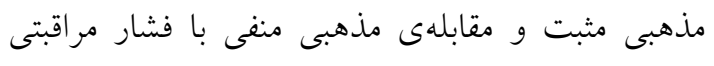

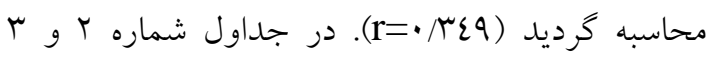

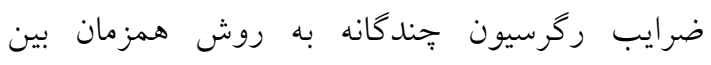

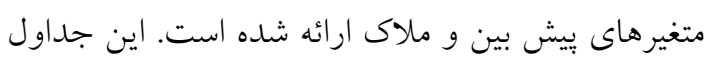

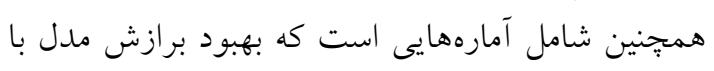

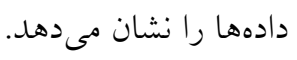

همانطور كه مشاهده مى مثود بين سبكى مقابلهى

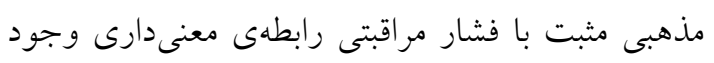

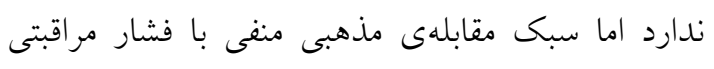

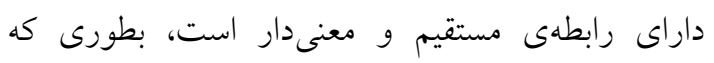

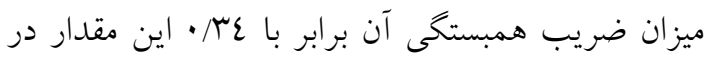

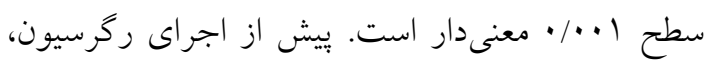

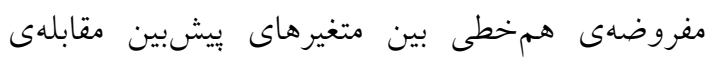

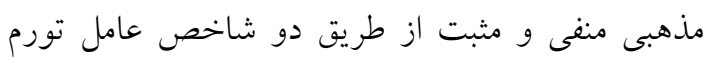

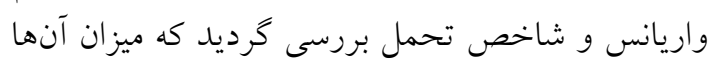

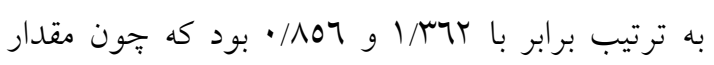

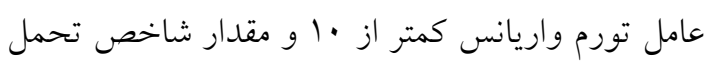

جدول شماره r. خلاصه التَوى رتحرسيون بين سبكهاى مقابلهى مذهبى مثبت و مقابلهى مذهبى منفى با فشار مراقبتى

\begin{tabular}{|c|c|c|c|}
\hline خطاى استاندارد بر آورد & R square & $\mathbf{R}$ & شاخص \\
\hline $17 / 0 r$. & $\cdot / M r$ & $\cdot \pi \varepsilon q$ & مقدار \\
\hline
\end{tabular}

براى بررسى معنى دارى اين مقدار نتايج آزمون تحليل بررسى جدول شماره r نشان مىدهد كه همبستخى

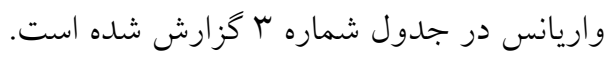

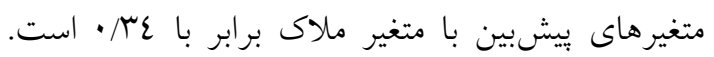

\begin{tabular}{|c|c|c|c|c|c|}
\hline $\mathbf{P}$ & $\mathbf{F}$ & ميانخين مجذورات & درجات آزادى & مجموع مجذورات & آزمون \\
\hline \multirow[t]{3}{*}{$\cdot / \cdot 1$} & $9 / M M$ & T79N/97T & r & orav/aro & ركرسيون \\
\hline & & $T V T / Q \varepsilon I$ & IEr & $r q \cdot r \cdot / \varepsilon q r$ & باقيمانده \\
\hline & & & 120 & $\varepsilon \sum \varepsilon \curlyvee N / \varepsilon \backslash \Lambda$ & كل \\
\hline
\end{tabular}


فشار مراقبتى و همجنين معنى دارى آنها را گزارش

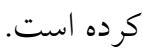

جدول شماره ץ بيانگر اين است كه متغيرهاى بيش بين تبيين معنى دارى از فشار مر اقبتى ارائه مى كنند.

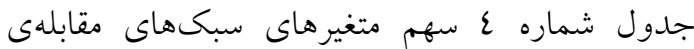
مذهبى مثبت و مقابلهى مذهبى منفى را در ييشبينى

\begin{tabular}{|c|c|c|c|c|c|}
\hline \multirow[t]{2}{*}{$\mathbf{P}$} & \multirow[t]{2}{*}{$\mathbf{T}$} & \multicolumn{3}{|c|}{ ضرايب استاندارد } & \multirow[t]{2}{*}{ ابعاد } \\
\hline & & $\beta$ & SE & B & \\
\hline • & $\cdot / 2 \mu \wedge$ &.$/ .0$ & • & $\cdot / 1 \varepsilon$. & مقابلهى مذهبى مثبت \\
\hline.$/ .1$ & $\varepsilon / \varepsilon \varepsilon \varepsilon$ & - ror & $1 / \cdot 1$. & $\varepsilon / \varepsilon \wedge$ & مقابلهى مذهبى منفى \\
\hline
\end{tabular}

راديوترايى دريافت مىكردند نيز تأييدكنندى اين

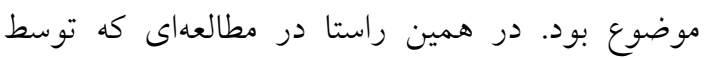
خنجرى و همكارانش (rV) در سال rال r r در دو مركز درمانى در شهر تهران صورت گرفته است، احساس

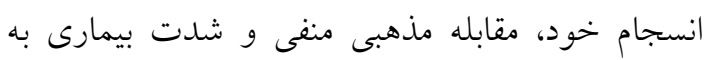
عنوان كاهش دهندهى كيفيت زندگى مراقبين بيماران

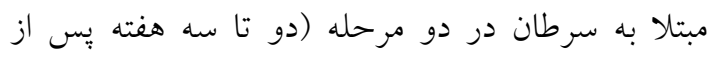
تشخيص سرطان و شش ماه پِ از تشخيص سرطان)

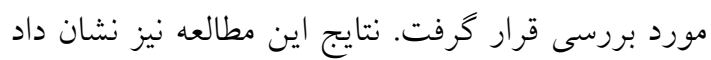
كه كيفيت زندكى مر اقبينى با مقابلهى مذهبى منفى بايين مردين

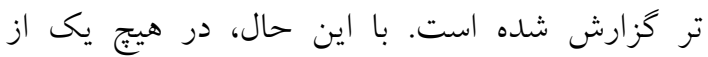
يزوهشها به رابطهى فشار مر اقبتى و سبكهاى مقابلهى مذهبى (مثبت و منفى) در مراقبين بيماران مراحل انتهايى يرداخته نشده است كه اين يُزوهش در جهت رفع اين خلأ، بر روى اين جامعه صورت كرفت. در تبيين يافتههاى يزوهشى مىتوان به اين نكته اشاره

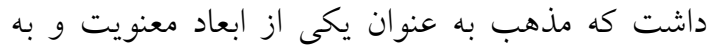
عنوان راهكارى مقابلهاى مىتواند در روند درمان منجر به كاهش تنشها شود. از همين رو، سازمان جهانى

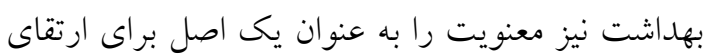

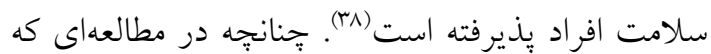
به بررسى نقش معنويت در مراقبين بيماران مراحل ابتدايى تومور مغزى در ايالت ينسيلوانياى آمريكا

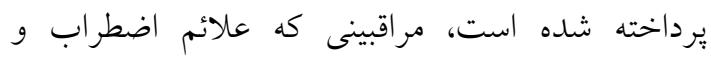

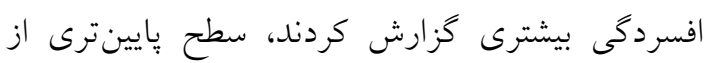

جدول شماره ع نشان مىدهد كه سبك مقابلهى مذهبى منفى ( فشار مراقبتى را ييشبينى مى كند ولى سبك مقابلهى

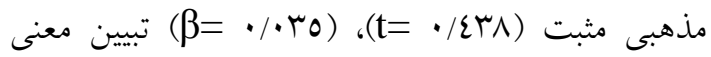
دارى از فشار مراقبتى نداشته و اين متغير قادر به يمبش بينى فشار مر اقبتى نيست.

\section{بحث و نتيجه كيرى}

يافتهاى يزوهش نشان نيجهيرى داد كه ميان سبك مقابلهى مذهبى مثبت با فشار مراقبتى رابطهى معنىدارى وجود ندارد اما سبك مقابلهى مذهبى منفى داراى رابطهاى مستقيم و معنى دار با فشار مراقبتى است؛ اين بدان معنى معنى

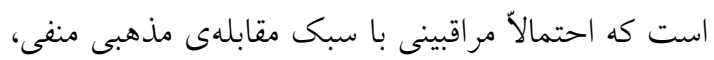

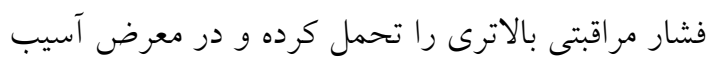
بيشترى قرار دارند. بنابراين، به كارگيرى سبك مقابلهى مذهبى منفى مىتواند منجر به كاهش سلامت روان و افزايش فشار مراقبتى كردد كه همسو با يزوهشهاى

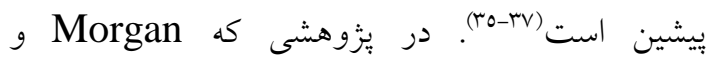

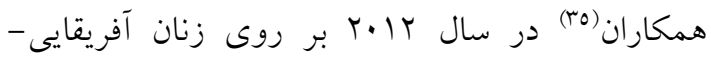
آمريكايى مبتلا به سرطان پِتان در كشور آمريكا انجام دادند به اين نتيجه رسيدند كه مقابلهى مذهبى منفى با باليا

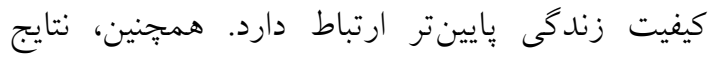

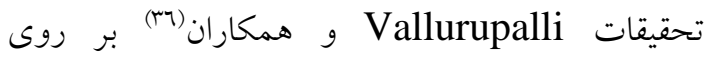
بيماران مبتلا به سرطان كه در مراكز راديوترايى بوستن

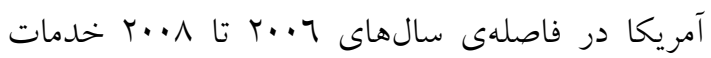


راهبردهاى مقابلهاى از جمله راهبردهاى مقابلهاى مثبت

$$
\text { را در جهت كنترل فشار مراقبتى كاهش دهند. }
$$

در نتيجه، بر اساس يافتههاى اين مطالعه، سبك مقابلهى مذهبى منفى تأثير منفى بر تحمل فشار مراقبين بيماران مبتلا به سرطان مرحلهى انتهايى داشته و اين افراد را در معرض احساس فشار بالاتر قرار مىدهد. بنابراين،

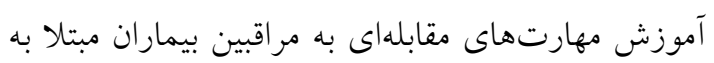
سرطان با تمركز بر بهبود راهبردهاى مقابلهاى مذهبى مثبت و كاهش استفاده از راهكارهاى منفى از همان مراحل ابتدايى، مىتواند كامى مؤثر در جهت كاهش فشار مراقبتى كه اين مراقبين طى فرايند درمان متحمل مىشوند، باشد. در نهايت، به نظر مىرسد اين اقدامات مىتواند به صورت غيرمستقيم، با تأثير بر زندكى مراقبين، در كيفيت همراهى و مراقبت آنها و همجينين وضعيت بيماران مؤثر واقع شود. در انجام اين يزوهش محدوديتهايى وجود داشت. انتخاب گروه نمونه به صورت در دسترس به علت شرايط ويزهى بيمارانى كه شركت كنند گان مراقبت از آن

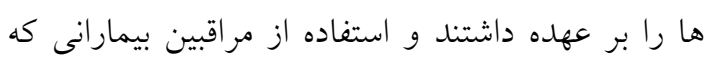
در بيمارستان بسترى هستند، امكان تعميم نتايج را با محدوديت مواجه مىسازد. همجنين، دشوار بودن

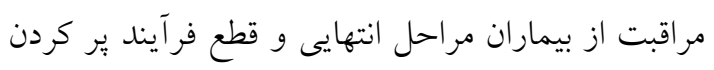
يرسشنامهها به علت وضعيت جسمانى بيماران، از جمله ديخر محدوديتهاى اين مطالعه بود. از اين رو بيشنهاد مىشود در يزوهشهاى آتى به جهت اطمينان در تعميم دهى، اين مطالعه با جمعيت مشابه (مراقبين بيماران مبتلا به سرطان مراحل انتهايى بسترى در بيمارستان) و ساير مراقبين (مراقبين بيماران مبتلا به سرطان مراحل انتهايى در منزل) تكرار شود. علاوه بر اين، بيشنهاد مى شود از نتايج بررسى حاضر در خدمات روانشناختى

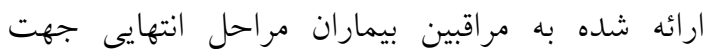
كاهش فشار مراقبتى آنها استفاده شود. از جمله نقاط قوت و نوآورى اين بيزوهش مىتوان به مطالعهى مراقبين بيماران مراحل انتهايى اشاره كرد كه به نظر مى
معنويت را دارا بودند(ra). در واقع، عدم وجود افكار معنوى و به طور خاص استفاده از راهكارهاى مقابلهاى مذهبى منفى (مانند داشتن تفكر خداى تنبيه كننده، تسليم فعالانه و منفعلانه، ناخشنودى معنوى و ...) مىتواند مانع معنادهى به مراقبتها و مجموعه اقداماتى باشد كه

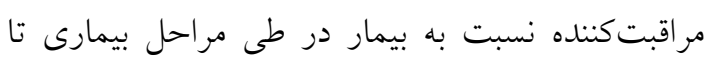
رسيدن به فاز انتهايى انجام مىدهد، كه خود موجب افزايش فشار مراقبتى آنها مىشود.

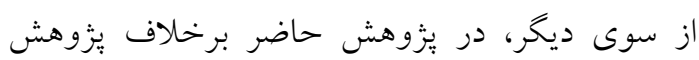
شريفى و فاتحىزاده(TN()، سبك مقابلهى مذهبى مثبت قادر به بيشبينى فشار مراقبتى در مراقبين نبود. تفاوت در نتايج اين مطالعه را مىتوان در نمونهاى كه اطلاعات از آن جمع آورى شده جستوجو كرد. نمونهى بيزوهش حاضر، مراقبين بيمارانى بودند كه در مرحلهى انتهايى بيمارى خود قرار داشتند و طول درمان، شدت علائم، احتمال فوت قريب الوقوع و خاتماهى درمانها ممكن است استفاده و كارايى مقابلهى مذهبى مثبت در اين افراد را تحت تأثير قرار داده باشد. از طرفى در يزوهشهاى كذشته فشار مراقبتى بيشتر در بيمارىهاى ديخرى همجيون نارسايى كليوى، عقبماندگى ذهنى و همجنين مسائل مربوط به نخهدارى سالمندان مورد بررسى قرار كرفته است. در واقع، مىتوان نتيجه گرفت كه عوامل مرتبط با فشار مراقبتى مراقبين بيماران، علاوه بر اين كه تحت تأثير مؤلفهاى فردى همراه بيمار است، بلكه موارد مرتبط با بيمار مانند نوع بيمارى، مرحلهى بيمارى و حتى نوع مقابلهى خود بيمار نيز در تجربهى فشار مراقب مىتواند مؤثر باشد. بنابراين،

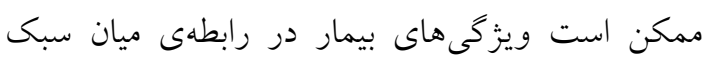
مقابلهى مذهبى و فشار مراقبتى اثركذار باشد كه اين مورد نيازمند انجام يزوهشهاى بيشتر است. همجنين، مراقبتهاى طولانى و كستردهاى كه مراقبين افراد مبتلا به سرطان مرحلهى انتهايى به علت طولانى

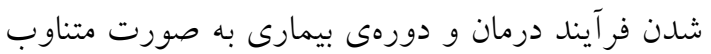
به آنها عرضه داشتهاند، مىتوانند اثربخشى و كارايى 


$$
\begin{aligned}
& \text { تقدير و تشكر } \\
& \text { اين مطالعه حاصل طرح مصوب در مركز توسعه }
\end{aligned}
$$

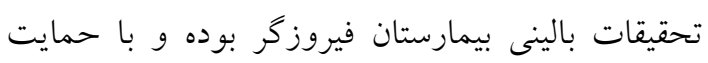

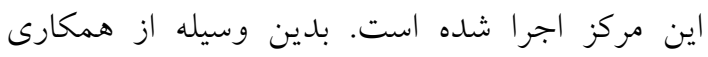

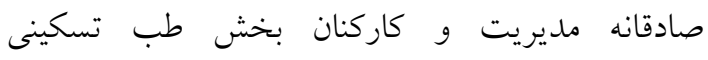

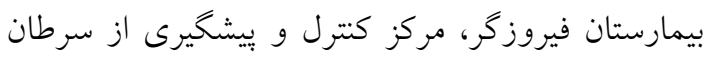

$$
\begin{aligned}
& \text { آلاء (مكسا) و حمايتهاى خانم دكتر زينب قائم يناه } \\
& \text { سباسگزاريم. (مكساء }
\end{aligned}
$$

\section{References}

1. Siegel R, Naishadham D, Jemal A. Cancer statistics for hispanics/latinos, 2012. CA Cancer J Clin. 2012;62(5):283-98.

2. Micheli A, Coebergh JW, Mugno E, Massimiliani E, Sant M, Oberaigner W, et al. European health systems and cancer care. Ann Oncol. 2003;14(suppl_5):v41-v60.

3. Moore MA, Eser S, Igisinov N, Igisinov S, Mohagheghi MA, Mousavi-Jarrahi A, et al. Cancer epidemiology and control in North-Western and Central Asia-past, present and future. Pancreas. 2010;4(4.2):0.7-1.9.

4. Zendehdel K, SEDIGHI Z, Hasanlou Z, Nahvijou A. Improving quality of cancer registration in Iran. Part1: evaluation and comparison of cancer registration results in the country. Hakim Res J. 2010;12: 42-48. [Persian]

5. Govina O, Kotronoulas G, Mystakidou K, Katsaragakis S, Vlachou E, Patiraki E. Effects of patient and personal demographic, clinical and psychosocial characteristics on the burden of family members caring for patients with advanced cancer in Greece. Eur J Oncol Nurs. 2015;19(1):81-8.

6. Chindaprasirt J, Limpawattana P, Pakkaratho P, Wirasorn K, Sookprasert A, Kongbunkiat K, et al. Burdens among caregivers of older adults with advanced cancer and risk factors. Asian Pac J Cancer Prev. 2014;15(4):1643-8.

7. Khatti Dizabadi F, Yazdani J, Eftekhar Ardebili H, Batebi A, Shojaezadeh D. The status of caregiving among informal caregivers of community-dwelling elderly. Journal of Mazandaran University of Medical Sciences. 2013;23(100):31-41. [Persian]

8. Girgis A, Lambert S, Johnson C, Waller A, Currow D. Physical, psychosocial, relationship, and economic burden of caring for people with cancer: a review. J Oncol Pract. 2012;9(4):197-202.

9. Salmani A, Ashketorab T, Hasanvand S. The Burden of Caregiverand Related Factorsof Oncology Patients of Shah Vali Hospital. Advances in Nursing \& Midwifery. 2015;24(2):117. [Persian]

10. Gage-Bouchard EA, Devine KA, Heckler CE. The relationship between socio-demographic characteristics, family environment, and caregiver coping in families of children with cancer. J Clin Psychol Med Settings. 2013;20(4):478-87.

11. Gaston-Johansson F, Lachica EM, Fall-Dickson JM, Kennedy MJ, editors. Psychological distress, fatigue, burden of care, and quality of life in primary caregivers of patients with breast cancer undergoing autologous bone marrow transplantation. Oncol Nurs Forum; 2004; 16;31(6):1161-9.

12. Park B, Kim SY, Shin J-Y, Sanson-Fisher RW, Shin DW, Cho J, et al. Prevalence and predictors of anxiety and depression among family caregivers of cancer patients: a nationwide survey of patient-family caregiver dyads in Korea. Support Care Cancer. 2013;21(10):2799807.

13. Yakar HK, Pinar R. Reliability and validity of Turkish version of the caregiver quality of life index cancer scale. Asian Pac J Cancer Prev. 2013;14(7):4415-9. 
14. Goldzweig G, Merims S, Ganon R, Peretz T, Altman A, Baider L. Informal caregiving to older cancer patients: preliminary research outcomes and implications. Ann Oncol. 2013;24(10):2635-40.

15. Ahmadi M, Rassouli M, Karami M, Abasszadeh A, Poormansouri S. Care burden and its Related Factors in Parents of Children with Cancer. Iran Journal of Nursing. 2018;31(111):40-51. [Persian]

16. Kahriman F, Zaybak A. Caregiver burden and perceived social support among caregivers of patients with cancer. Asian Pac J Cancer Prev. 2015;16(8):3313-7.

17. Wang J, Shen N, Zhang X, Shen M, Xie A, Howell D, et al. Care burden and its predictive factors in parents of newly diagnosed children with acute lymphoblastic leukemia in academic hospitals in China. Support Care Cancer. 2017;25(12):3703-13.

18. Wang LJ, Zhong WX, Ji XD, Chen J. Depression, caregiver burden and social support among caregivers of retinoblastoma patients in China. Int J Nurs Pract. 2016;22(5):478-85.

19. Choi YS, Hwang SW, Hwang IC, Lee YJ, Kim YS, Kim HM, et al. Factors associated with quality of life among family caregivers of terminally ill cancer patients. Psycho-Oncology. 2016;25(2):217-24.

20. Taheri-Kharameh Z, Saeid Y, Ebadi A. The relationship between religious coping styles and quality of life in patients with coronary artery disease. Iranian Journal of Cardiovascular Nursing. 2013;2(1):24-32. [Persian]

21. Pargament KI, Smith BW, Koenig HG, Perez L. Patterns of positive and negative religious coping with major life stressors. J Sci Study Relig. 1998:710-24.

22. Pargament K. The Psychology of Religion and Coping, New York. Guilford Press Prati, G, \& Pietrantoni, L(2009) Optimism, social support, and coping strategies as factors contributing to posttraumatic growth: A meta-analysis Journal of Loss and Trauma. 1997;14:364-88.

23. Pargament KI, Koenig HG, Perez LM. The many methods of religious coping: Development and initial validation of the RCOPE. J Clin Psychol. 2000;56(4):519-43.

24. Kazemi MS. The relationship between religious coping strategies and mental health in MS patient. Procedia-Social and Behavioral Sciences. 2010;5:1387-9. [Persian]

25. Koenig HG, Pargament KI, Nielsen J. Religious coping and health status in medically ill hospitalized older adults. The Journal of nervous and mental disease. 1998;186(9):513-21.

26. Pargament KI, Koenig HG, Tarakeshwar N, Hahn J. Religious coping methods as predictors of psychological, physical and spiritual outcomes among medically ill elderly patients: A twoyear longitudinal study. J Health Psychol. 2004;9(6):713-30.

27. Fitchett G, Rybarczyk BD, DeMarco GA, Nicholas JJ. The role of religion in medical rehabilitation outcomes: A longitudinal study. Rehabil Psychol. 1999;44(4):333-53.

28. Sharifi M, Fatehizade M. Correlation between religious coping with deppression and caregiver burnout in family caregivers. Modern Care Journal. 2012;9(4):327-35. [Persian]

29. Nemati S, Rassouli M, Ilkhani M, Baghestani AR. Perceptions of family caregivers of cancer patients about the challenges of caregiving: a qualitative study. Scand J Caring Sci. 2018;32(1):309-16.

30. Tabchnick BG, Fidell LS. Using multivariate statistics. Boston: Allyin \& Bacon. $5^{\text {th }}$ ed. Boston: Pearson Education; 2006.

31. Novak M, Guest C. Application of a multidimensional caregiver burden inventory. The gerontologist. 1989;29(6):798-803.

32. Abbasi A, Shamsizadeh M, Asayesh H, Rahmani H, Hosseini S, Talebi M. The relationship between caregiver burden with coping strategies in Family caregivers of cancer patients. Iranian Nursing Scientific Association. 2013;1(3):62-71. [Persian]

33. Pargament KI, Smith BW, Koenig HG, Perez L. Patterns of positive and negative religious coping with major life stressors. Journal for the scientific study of religion. 1998:710-24.

34. Shahabizadeh F, Mazaheri MA. Perceived Childhood Attachment, Family Functioning and Religious Coping. Development psychology: Iranian psychologists. 2011; 8: 221-34. [Persian]

35. Morgan PD, Gaston-Johansson F, Mock V. Spiritual well-being, religious coping, and the quality of life of African American breast cancer treatment: a pilot study. ABNF $J$. 2006;17(2):73-7. 
36. Vallurupalli MM, Lauderdale MK, Balboni MJ, Phelps AC, Block SD, Ng AK, et al. The role of spirituality and religious coping in the quality of life of patients with advanced cancer receiving palliative radiation therapy. The journal of supportive oncology. 2012;10(2):81-7.

37. Khanjari S, Oskouie F, Langius-Eklöf A. Lower sense of coherence, negative religious coping, and disease severity as indicators of a decrease in quality of life in Iranian family caregivers of relatives with breast cancer during the first 6 months after diagnosis. Cancer Nurs. 2012;35(2):148-56.

38. Organization WH. International statistical classification of diseases and related health problems: World Health Organization; 2004.

39. Newberry AG, Choi C-WJ, Donovan HS, Schulz R, Bender C, Given B, et al., editors. Exploring spirituality in family caregivers of patients with primary malignant brain tumors across the disease trajectory. Oncol Nurs Forum; 2013; 40(3): 1-12. 